\title{
ESTATUTO DA PESSOA COM DEFICIÊNCIA, AÇÕES COLETIVAS E SERVENTIAS EXTRAJUDICIAIS DE NOTAS E DE REGISTROS
}

\author{
GUSTAVO HENRIQUE MATTOS VOLTOLINI* \\ JUVÊNCIO BORGES SILVA**
}

\begin{abstract}
Resumo
O Estatuto da Pessoa com Deficiência (Lei $n^{\circ}$ 13.146/2015) trouxe inovações, especialmente quanto aos dispositivos que tratam da incapacidade, ao casamento de pessoas com deficiência e no tratamento que deve ser dado a estas. $\mathrm{O}$ referido estatuto também traz disposições específicas para as serventias extrajudiciais de notas e de registros. Todas essas novidades repercutem nos direitos e interesses das pessoas portadoras de deficiência, inclusive interesses coletivos, difusos, individuais homogêneos e individuais indisponíveis, que podem dar ensejo ao ajuizamento de ações coletivas visando à proteção de tais direitos por atos praticados nas mencionadas serventias.
\end{abstract}

Palavras-chave: Estatuto; Pessoa; Deficiência; Ações coletivas; Serventias extrajudiciais de notas e de registros.

\section{STATUTE OF THE DISABLED PERSON, CLASS ACTIONS AND OUT-OF-COURT NOTES AND RECORDS}

\begin{abstract}
The Disabled Persons Statute (Law No. 13,146 / 2105) has brought innovations, especially with regard to disability provisions, marriage of persons with disabilities and the treatment that should be given to them. This statute also provides specific provisions for notaries. All these new developments have repercussions on the rights and interests of persons with disabilities, including collective, diffuse, individual homogeneous and individual interests, which may give rise to the filing of collective actions aiming at the protection of such rights by acts practiced in said services.
\end{abstract}

Keywords: Statute; Person; Disabled; Class actions; Out-of-court notes and records

\footnotetext{
* Mestrando em Direitos Coletivos e Cidadania pela Universidade de Ribeirão Preto (UNAERP), Pós-graduado em Direito Civil pela Faculdade Internacional Signorelli (FISIG) graduado em Direito pela Universidade Federal de Santa Catarina (UFSC), Oficial de Registro de Imóveis, Títulos e Documentos, Civil de Pessoa Jurídica e Civil das Pessoas Naturais e de Interdições e Tutelas da Sede da Comarca de Colina/SC. Email: gustavovoltolini@hotmail.com

** Pós-doutor em Direito pela Faculdade de Direito da Universidade de Coimbra, Doutor pela UNESP, Mestre pela UNICAMP, Graduado em Direito pela Faculdade de Direito de Franca, Graduado em Ciências Sociais pela Faculdade de Filosofia de Passos, Docente do Programa de Mestrado em Direitos Coletivos e Cidadania da Universidade de Ribeirão Preto. Email: juvencioborges@gmail.com
}

Rev. de Processo, Jurisdição e Efetividade da Justiça | e-ISSN: 2525-9814| Maranhão | v. 3 | n. 2 | p. 36 - 53| Jul/Dez. 2017. 


\section{INTRODUÇÃO}

O presente trabalho tem por objetivo abordar o tema do Estatuto da Pessoa com Deficiência (Lei $\mathrm{n}^{\mathrm{o}}$ 13.146/2015), abordando, principalmente a nova ótica inclusiva das pessoas com deficiência, a possibilidade de ajuizamento de ações coletivas para a proteção de direitos de tais pessoas e as mudanças trazidas pelo Estatuto que refletirão na prática do ofício de notários e registradores.

Assim, pretende-se fazer uma crítica a alguns pontos do texto legal aprovado e demonstrar algumas modificações trazidas e que devem ser cumpridas por notários e registradores, sob pena de ajuizamento de ações coletivas.

Na primeira parte abordar-se-á, o Estatuto da Pessoa com Deficiência, sua intenção de efetuar a inclusão social das pessoas com deficiência, as mudanças nas normas da incapacidade civil e da possibilidade de realizar matrimônio.

Posteriormente, discorrer-se-á sobre as ações coletivas para de proteção de interesses coletivos, difusos, individuais homogêneos e individuais indisponíveis das pessoas com deficiência e o papel do Ministério Público quanto a tais interesses.

Em um terceiro momento se fará uma exposição sobre as serventias extrajudiciais de notas e de registros, as normas especificamente direcionadas a referidas serventias e outras inovações que repercutem na prática notarial e registral.

Por fim, verificar-se-á as determinações que o Estatuto da Pessoa com Deficiência impõe que sejam adotadas pelas serventias de notas e de registros, que se descumpridas podem resultar no ajuizamento de ações coletivas, e algumas possíveis dificuldades que serão encontradas pelos notários e registradores na aplicação do Estatuto.

Vale destacar que a lei é nova e ainda há muito a ser discutido e pacificado sobre a aplicação do Estatuto da Pessoa com Deficiência, especialmente sobre a incapacidade e o casamento.

O presente artigo se orientará pelo método analítico-dedutivo, em que se busca através de pesquisa bibliográfica, artigos científicos, leis, jurisprudências, doutrinas, a fim de se chegar a conclusões sobre o objeto em análise. 


\section{O ESTATUTO DA PESSOA COM DEFICIÊNCIA}

A Lei $\mathrm{n}^{\mathrm{o}}$ 13.146, de 6 de julho de 2015, denominada Estatuto da Pessoa com Deficiência, instituiu a Lei Brasileira de Inclusão da Pessoa com Deficiência e entrou em vigor após o período após 180 dias de sua publicação oficial.

O Estatuto da Pessoa com Deficiência teve como base a Convenção sobre os Direitos das Pessoas com Deficiência e seu Protocolo Facultativo, ratificados no Brasil pelo Decreto Legislativo $\mathrm{n}^{\mathrm{o}}$ 186, de 9 de julho de 2008, entrando em vigor no plano externo para o Brasil em 31 de agosto de 2008 , em conformidade com o procedimento previsto no $\S 3^{\circ}$ do art. $5^{\circ}$ da Constituição Federal, (que equivale à emenda constitucional a convenção sobre direitos humanos que for aprovada, em cada Casa do Congresso Nacional, em dois turnos, por três quintos dos votos dos respectivos membros), e promulgados pelo Decreto $\mathrm{n}^{\circ}$ 6.949, de 25 de agosto de 2009, data de início de sua vigência no plano interno. Nas palavras de Luciano Lopes Passarelli (2016 p. 347): "Vê-se, assim, que muitos aspectos que agora são objeto do novo Estatuto já estavam em vigor no Brasil, e com dignidade de Emenda Constitucional".

De acordo com o Estatuto, considera-se pessoa com deficiência aquela que tem impedimento de longo prazo de natureza física, mental, intelectual ou sensorial, o qual, em interação com uma ou mais barreiras, pode obstruir sua participação plena e efetiva na sociedade em igualdade de condições com as demais pessoas (art. $2^{\circ}$ ).

O Estatuto da Pessoa com Deficiência foi elaborado e aprovado com o objetivo de assegurar uma tutela jurídica capaz de promover a inclusão social e a proteção à dignidade de todas as pessoas com deficiência. (PASQUAL; PASQUAL, 2016, p. 275) Deve-se passar da ótica assistencialista, a qual considerava que a pessoa portadora de deficiência era portadora de uma enfermidade e deveria ser tratada, para uma ótica inclusiva garantindo o pleno exercício dos direitos humanos da pessoa com deficiência.

Sobre o tema, Flávia Piovesan explica as quatro fases da história da construção dos direitos humanos da pessoa com deficiência, que começou sendo considerada um castigo divino, depois passou a ser escondida pela família, passando pela fase assistencialista até chegar à última fase, pautada pelos direitos humanos e pela inclusão social: 
A história da construção dos direitos humanos das pessoas com deficiência compreende quatro fases: (a) uma fase de intolerância em relação às pessoas com deficiência, em que a deficiência simbolizava impureza, pecado, ou mesmo castigo divino; (b) uma fase marcada pela invisibilidade das pessoas com deficiência; (c) uma terceira fase orientada por uma ótica assistencialista, pautada na perspectiva médica e biológica de que a deficiência era uma 'doença a ser curada', sendo o foco centrado no indivíduo 'portador da enfermidade' e, (d) finalmente uma quarta fase orientada pelo paradigma dos direitos humanos, em que emergem os direitos à inclusão social, com ênfase na relação da pessoa com deficiência e do meio em que ela se insere, bem como na necessidade de eliminar os obstáculos e barreiras superáveis, sejam elas culturais, físicas ou sociais, que impeçam o pleno exercício dos direitos humanos. Isto é, nessa quarta fase, o problema passa a ser a relação do indivíduo e do meio, este assumido como uma construção coletiva. Nesse sentido, esta mudança paradigmática aponta os deveres do Estado em remover e eliminar os obstáculos que impeçam o pleno exercício de direitos das pessoas com deficiência, viabilizando o desenvolvimento de suas potencialidades, com autonomia e participação. (PIOVESAN, 2015, p. 118-119)

O espírito do Estatuto é o da superação do assistencialismo e eliminação das barreiras, assegurando à pessoa com deficiência a dignidade, a civilidade e a plena participação na sociedade. (LAGO, 2016, p. 312)

O Estatuto da Pessoa com Deficiência alterou os artigos $3^{\circ}$ e $4^{\circ}$ do Código Civil que tratam sobre a incapacidade. A intenção da alteração foi a retirar a deficiência, por si só, como causa de incapacidade. Neste sentido:

[...] o Estatuto pretendeu eliminar a previsão genérica da deficiência como hipótese objetiva de incapacidade. Ou seja, desatrelou-se a deficiência do conceito de incapacidade. E isso tem um objetivo claro: a eliminação da interdição total ou completa da pessoa por motivo de enfermidade ou deficiência mental. (OLGADO, 2016, p. 333)

Desta forma, no artigo $3^{\circ}$, que trata da incapacidade absoluta, pelo novo texto alterado, são considerados absolutamente incapazes apenas os menores de 16 anos. Os outros dois casos de incapacidade antes previstos eram: a) os do que, por enfermidade ou deficiência mental, não tiverem o necessário discernimento, que foi revogado; b) os do que, mesmo por causa transitória, não puderem exprimir sua vontade, que passou a ser causa de incapacidade relativa.

Desta forma, conclui Flávio Tartuce: "Em suma, não existe mais, no sistema privado brasileiro, pessoa absolutamente incapaz que seja maior de idade. Como consequência, não há que se falar mais em ação de interdição absoluta no nosso sistema civil, pois os menores não são interditados.” (TARTUCE, 2015) Porém, a interdição por incapacidade relativa, bem como o registro desta interdição no Livro E do Registro Civil das Pessoas Naturais continua a existir. 
O artigo $4^{\circ}$, por sua vez, que trata da incapacidade relativa, manteve entre os relativamente incapazes os pródigos, os maiores de dezesseis e menores de dezoito anos, os ébrios habituais e os viciados em tóxico. A antiga previsão dos excepcionais, sem desenvolvimento mental completo, e dos que, por deficiência mental, tenham o discernimento reduzido foi revogada e foi, como já mencionado, acrescentado entre os relativamente incapazes aqueles que, por causa transitória ou permanente, não puderem exprimir sua vontade.

Portanto, fica claro que o objetivo do Estatuto foi acabar com a previsão de ser a deficiência a causa da incapacidade e, por tal razão, foram revogados os dispositivos que mencionavam qualquer tipo de incapacidade (excepcionais, sem desenvolvimento mental completo, os que por deficiência mental, tenham o discernimento reduzido, e os excepcionais, sem desenvolvimento mental completo). Sobre este assunto:

[...] o fato de um sujeito possuir transtorno mental de qualquer natureza, não faz com que ele, automaticamente, se insira no rol dos incapazes. É um passo importante na busca pela promoção da igualdade dos sujeitos portadores de transtorno mental, já que se dissocia o transtorno da necessária incapacidade. [...] A mudança apontada não implica, entretanto, que o portador de transtorno mental não possa vir a ter a sua capacidade limitada para a prática de certos atos. Mantém-se a possibilidade de que venha ele a ser submetido ao regime de curatela. (REQUIÃO, 2015)

O que faz ser uma pessoa incapaz não é deficiência, mas a ausência de discernimento, a inaptidão para manifestar a vontade de forma livre e consciente, que demonstre o querer agir e conhecer os efeitos da ação. (OLGADO, 2016, p. 335). A pessoa com deficiência, assim como qualquer outra pessoa maior de dezoito anos, é capaz até que se prove em contrário de que ela não consiga manifestar sua vontade.

Reforçando as ideias de plena participação da pessoa com deficiência na vida em sociedade e de que a deficiência não é, por si só, causa de incapacidade, o Estatuto determinou expressamente que a deficiência não afeta a plena capacidade civil da pessoa, a qual pode inclusive se casar e constituir união estável (art $6^{\circ}$, inciso I).

Diante das inovações trazidas pelo Estatuto, fica ainda mais evidenciada a importância do ajuizamento de ações coletivas objetivando proteção de interesses coletivos, difusos, individuais homogêneos e individuais indisponíveis das pessoas com deficiência.

\section{AÇÕES COLETIVAS E A PESSOA COM DEFICIÊNCIA}


É muito importante a proteção dos interesses das pessoas com deficiência, especialmente com o fim de garantir inclusão social, acessibilidade e dignidade. O Estatuto da Pessoa com Deficiência reforça essa necessidade. Ivana Assis Cruz dos Santos relata que:

Existe um grande número de pessoas com deficiência no mundo e no Brasil e algumas delas, mesmo diante de tantos impasses e preconceitos, conseguem participar e contribuir ativamente em diversas atividades sociais. Contudo, como a discriminação ainda é grande, muitos acabam sendo excluídos da convivência com a comunidade e até mesmo com os parentes. (SANTOS, 2015)

A Ação Civil Pública é instrumento eficaz para a efetiva proteção das pessoas com deficiência. (RAGAZZI, 2010) Neste sentido, a Lei n. 7.853 de 1989 instituiu a tutela jurisdicional de interesses coletivos ou difusos dessas pessoas e disciplinou a atuação do Ministério Público. Em seu artigo $3^{\circ}$, caput, determinava que "as ações civis públicas destinadas à proteção de interesses coletivos ou difusos das pessoas portadoras de deficiência poderão ser propostas pelo Ministério Público, pela União, Estados, Municípios e Distrito Federal; por associação constituída há mais de 1 (um) ano, nos termos da lei civil, autarquia, empresa pública, fundação ou sociedade de economia mista que inclua, entre suas finalidades institucionais, a proteção das pessoas portadoras de deficiência”.

Com o advento do Estatuto da Pessoa com Deficiência, a referida Lei 7.853/1989 continuou em vigor, mas o Estatuto alterou o texto do citado artigo $3^{\circ}$, caput, que passou a contar com a seguinte redação: "as medidas judiciais destinadas à proteção de interesses coletivos, difusos, individuais homogêneos e individuais indisponíveis da pessoa com deficiência poderão ser propostas pelo Ministério Público, pela Defensoria Pública, pela União, pelos Estados, pelos Municípios, pelo Distrito Federal, por associação constituída há mais de 1 (um) ano, nos termos da lei civil, por autarquia, por empresa pública e por fundação ou sociedade de economia mista que inclua, entre suas finalidades institucionais, a proteção dos interesses e a promoção de direitos da pessoa com deficiência".

A Lei ${ }^{\circ} 7.853 / 1989$ outorga praticamente os mesmos legitimados da Lei de Ação Civil Pública, mas as entidades (associação, autarquia, empresa pública, fundação e sociedade de economia mista) devem incluir entre suas finalidades a proteção a pessoas portadoras de deficiências. (MARCO; SANDRINI, 2011)

Rev. de Processo, Jurisdição e Efetividade da Justiça | e-ISSN: 2525-9814| Maranhão | v. 3 | n. 2 | p. 36 - 53| Jul/Dez. 2017 
Note-se, também, que o art. $3^{\circ}$ da Lei 7.853/1989, com a redação dada pelo Estatuto da Pessoa com Deficiência, além dos interesses coletivos ou difusos, incluiu também expressamente a previsão da proteção de direitos individuais homogêneos e individuais indisponíveis. E houve, outrossim, a mudança do termo "ações civis públicas" (utilizado na redação do artigo antes do advento do Estatuto da Pessoa com Deficiência) por "medidas judiciais" (utilizado na nova redação do artigo após o advento do mencionado Estatuto), o que reforça a ideia de que a proteção aos interesses das pessoas com deficiência pode se dar pelo ajuizamento de ação civil pública, de outros ações coletivas e até de ações individuais.

O Ministério Público deve intervir, obrigatoriamente, nas ações públicas, coletivas ou individuais, em que se discutam interesses relacionados à deficiência das pessoas (art. $5^{\circ}$ da Lei 7.853/1989). ${ }^{1}$

Prevê, ainda, a mencionada Lei, em seu art. $6^{\circ}$, que o Ministério Público pode instaurar inquérito civil ou requisitar, de qualquer pessoa física ou jurídica, pública ou particular, certidões, informações, exame ou perícias, no prazo que assinalar, não inferior a 10 (dez) dias úteis. ${ }^{2}$

\footnotetext{
${ }^{1}$ Dispõe a Lei $n^{\circ} 7.853 / 1989$, nos $\S$ do artigo $3^{\circ}$ e no artigo 4: $\S 1^{\circ}$ Para instruir a inicial, o interessado poderá requerer às autoridades competentes as certidões e informações que julgar necessárias.

$\S 2^{\circ}$ As certidões e informações a que se refere o parágrafo anterior deverão ser fornecidas dentro de 15 (quinze) dias da entrega, sob recibo, dos respectivos requerimentos, e só poderão se utilizadas para a instrução da ação civil.

$\S 3^{\circ}$ Somente nos casos em que o interesse público, devidamente justificado, impuser sigilo, poderá ser negada certidão ou informação.

$\S 4^{\circ}$ Ocorrendo a hipótese do parágrafo anterior, a ação poderá ser proposta desacompanhada das certidões ou informações negadas, cabendo ao juiz, após apreciar os motivos do indeferimento, e, salvo quando se tratar de razão de segurança nacional, requisitar umas e outras; feita a requisição, o processo correrá em segredo de justiça, que cessará com o trânsito em julgado da sentença.

$\S 5^{\circ}$ Fica facultado aos demais legitimados ativos habilitarem-se como litisconsortes nas ações propostas por qualquer deles.

$\S 6^{\circ} \mathrm{Em}$ caso de desistência ou abandono da ação, qualquer dos colegitimados pode assumir a titularidade ativa.

Art. $4^{\circ}$ A sentença terá eficácia de coisa julgada oponível erga omnes, exceto no caso de haver sido a ação julgada improcedente por deficiência de prova, hipótese em que qualquer legitimado poderá intentar outra ação com idêntico fundamento, valendo-se de nova prova.

$\S 1^{\circ}$ A sentença que concluir pela carência ou pela improcedência da ação fica sujeita ao duplo grau de jurisdição, não produzindo efeito senão depois de confirmada pelo tribunal.

$\S 2^{\circ}$ Das sentenças e decisões proferidas contra o autor da ação e suscetíveis de recurso, poderá recorrer qualquer legitimado ativo, inclusive o Ministério Público.

${ }^{2}$ Estabelecem os $\S \S$ do artigo $6^{\circ}$ da Lei $n^{\circ} 7.853 / 1989: \S 1^{\circ}$ Esgotadas as diligências, caso se convença o órgão do Ministério Público da inexistência de elementos para a propositura de ação civil, promoverá fundamentadamente o arquivamento do inquérito civil, ou das peças informativas. Neste caso, deverá remeter a reexame os autos ou as respectivas peças, em 3 (três) dias, ao Conselho Superior do Ministério Público, que os examinará, deliberando a respeito, conforme dispuser seu Regimento.

$\S 2^{\circ}$ Se a promoção do arquivamento for reformada, o Conselho Superior do Ministério Público designará desde logo outro órgão do Ministério Público para o ajuizamento da ação.
}

Rev. de Processo, Jurisdição e Efetividade da Justiça | e-ISSN: 2525-9814| Maranhão | v. 3 | n. 2 | p. 36 - 53| Jul/Dez. 2017. 
Aplicam-se à ação civil pública prevista na Lei 7.853/1989, no que couber, os dispositivos da lei da ação civil pública (Lei no 7.347/1985).

De acordo com o art. $7^{\circ}$, caput, do Estatuto da Pessoa com Deficiência, é dever de todos comunicar à autoridade competente qualquer forma de ameaça ou de violação aos direitos da pessoa com deficiência.

Portanto, fica evidente a importância da proteção dada aos interesses de pessoas com deficiência, com possibilidade do ajuizamento de ações coletivas, instauração de inquérito civil, intervenção obrigatória do Ministério Público nas ações em que se discutam interesses relacionados à deficiência e com o dever de todos de informar qualquer ameaça ou violação aos direitos da pessoa com deficiência.

\section{AS SERVENTIAS EXTRAJUdiciais E O ESTATUTO DA PESSOA COM DEFICIÊNCIA}

De acordo com o artigo 236 da Constituição Federal, os serviços notariais e de registro são exercidos em caráter privado, por delegação do Poder Público. Ou seja, tais serviços não são prestados diretamente pelo Estado, mas sim pelos delegatários, denominados oficiais de registro e tabeliães. É o que explica Luiz Guilherme Loureiro:

Atividades notariais e de registro constituem funções públicas que, por força do disposto
no art. 236 da Constituição, não são executados diretamente pelo Estado, mas por meio
de delegação a particulares. Os notários ou registradores, portanto, são profissionais do
direito que exercem uma função pública delegada pelo Estado. Tais atividades são
desempenhadas em caráter privado, sem que os profissionais que as exerçam integrem o
corpo orgânico do Estado. (LOUREIRO, 2014, p. 1)

O ingresso na atividade notarial e de registro se dá por concurso público de prova e títulos (art. 236, $\S 3^{\circ}$ ) e os tabeliães e oficiais de registro são agentes públicos, eis que prestam um serviço público delegado a eles por meio de concurso público.

Contudo, os tabeliães e oficiais de registro não são servidores públicos nem concessionários ou permissionários de serviço público, são uma categoria sui generis por isso disciplinada de forma individualizada no mencionado artigo 236 da Constituição Federal. Nesse sentido: 
Eis sua condição híbrida, na medida em que não são nem servidores, nem concessionários, embora possuam os notários e registradores características que ora os aproximam dos servidores públicos ora dos concessionários. Estreme de dúvidas, ao menos neste sentido, se polarizarmos, de um lado, os servidores públicos em sentido estrito e, de outro, os concessionários de serviços públicos, a função notarial e registral caracterizará tertium genus. (MAFFINI, 2015, p. 181)

As atividades notariais e de registro são de titularidade do Estado, porém a pessoa jurídica de direito público não a exerce diretamente, sendo tais atividades delegadas ao particular (LOUREIRO, 2014), que é necessariamente pessoa natural, não podendo ser pessoa jurídica.

A Lei $n^{\circ} 8.935 / 1994$ disciplina as atividades exercidas pelos oficiais de registro e tabeliães. De acordo com a mencionada lei, os tabeliães, também chamados de notários, e os oficiais de registro, também denominados registradores, são profissionais do direito, dotados de fé pública, a quem é delegado o exercício da atividade notarial e de registro (art. $\left.1^{\circ}\right)$.

São as seguintes as espécies mais comuns de serventias extrajudiciais: tabelião de notas e tabelião de protestos de títulos (atividades notariais) e oficial de registro de imóveis, oficial de registro de títulos e documentos e civil das pessoas jurídicas e oficiais de registro civil das pessoas naturais e de interdições e tutelas (atividades registrais), Além desses mais comuns há também os oficias de registro de distribuição e tabeliães e oficiais de registros de contratos marítimos, conforme estabelecido no artigo $5^{\circ}$ da Lei $n^{\circ} 8.935 / 1994$.

O Estatuto da Pessoa com Deficiência possui um artigo específico para as serventias extrajudiciais de notas e de registros. É o artigo 83, que sem seu caput estabelece: "Os serviços notariais e de registro não podem negar ou criar óbices ou condições diferenciadas à prestação de seus serviços em razão de deficiência do solicitante, devendo reconhecer sua capacidade legal plena, garantida a acessibilidade". E seu parágrafo único determina: "O descumprimento do disposto no caput deste artigo constitui discriminação em razão de deficiência". José Lucas Rodrigues Olgado cita algumas proibições decorrentes do mencionado art. 83:

[...] proibição de atitudes intencionalmente preconceituosas, como, por exemplo, negar
ou dificultar o atendimento a pessoa deficiente alegando não possuir acessibilidade
mínima exigida em lei; cobrar valores excedentes não previstos em tabela, alegando
necessidade de maior tempo e atenção a pessoa deficiente, entre outras hipóteses de
mesma natureza. (OLGADO, 2014, p. 339) Há, inclusive, no artigo 88 do Estatuto um crime doloso previsto para quem pratica induz ou incita discriminação de pessoa em razão de sua deficiência, com pena prevista de 
reclusão de um a três anos e multa. Portanto, a discriminação da pessoa com deficiência por notário, registrador ou seus prepostos pode gerar sanções administrativas, penais e civis, podendo até mesmo dar azo ao ajuizamento de ação coletiva para proteção dos interesses das pessoas com deficiência. Sobre o tema, escreve Christiano Cassetari:

A discriminação pode gerar vários tipos de sanções, a saber: a) pena de reclusão pela prática do crime de discriminação, tipificado no art. 88 do próprio estatuto da pessoa com deficiência: "Art. 88. Praticar, induzir ou incitar discriminação de pessoa em razão de sua deficiência. Pena - reclusão, de 1 (um) a 3 (três) anos, e multa". b) dever de indenizar por dano moral, em razão da prática de um ato ilícito (art. 186 do CC/2002), ou por agir com abuso de direito (art. 187 do CC/2002). c) perda da delegação (art. 32, IV, da Lei 8.935/1994) pela prática de infração disciplinar, descrita no art. 31 da Lei 8.935/1994: “Art. 31 São infrações disciplinares que sujeitam os notários e os oficiais de registro às penalidades previstas nesta lei: I - a inobservância das prescrições legais ou normativas; (...)". Notem que se ficar tipificada a conduta de discriminação, haverá espaço para sanções penal, cível e administrativa. (CASSETARI, 2016, p. 264-265)

Além do mencionado art. 83, os notários e registradores nas serventias extrajudiciais devem garantir a acessibilidade das pessoas com deficiência e o atendimento prioritário destas. Em razão da mudança ocorrida no sistema de incapacidade civil trazida pelo Estatuto, outros ramos do Direito também são afetados com mudanças. É o que explica Pablo Stolze:

Certamente, o impacto do novo diploma se fará sentir em outros ramos do Direito brasileiro, inclusive no âmbito processual. Destacamos, a título ilustrativo, o art. $8^{\circ}$ da Lei 9.099 de 1995, que impede o incapaz de postular em Juizado Especial. A partir da entrada em vigor do Estatuto, certamente perderá fundamento a vedação, quando se tratar de demanda proposta por pessoa com deficiência. (STOLZE, 2015)

Assim, o impacto do Estatuto é sentido também pelos notários e pelos registradores que aplicarão também as novas regras trazidas, especialmente em relação ao casamento, realizado no Registro Civil das Pessoas Naturais, e incapacidade.

A incapacidade será objeto de contato com os notários, por exemplo, quando forem fazer escritura, eis que de acordo com o artigo 215 do Código Civil a escritura pública deve conter o reconhecimento da capacidade e a manifestação clara das vontades das partes (incisos II e IV). No Registro Civil das Pessoas Naturais se continuará a realizar o registro de interdição (de incapacidade relativa) no Livro E.

A aplicação do Estatuto da Pessoa com Deficiência por notários e registradores passará por algumas dificuldades práticas, tendo em vista a novidade da lei, até que se pacifique o entendimento ou se promova alterações legislativas. 


\section{DIFICULdADES PRÁTICAS NA APLICAÇÃO DO ESTATUTO DA PESSOA COM DEFICIÊNCIA}

Em algumas situações, o Estatuto da Pessoa com Deficiência, por considerar as pessoas com deficiência capazes, indiretamente faz com que a proteção antes dada a elas (justamente por antes serem consideradas incapazes) desapareça. Sobre o assunto, ilustra Ivana Assis Cruz dos Santos:

Outrossim, outro efeito da plena capacidade das pessoas com deficiência recaiu sobre a responsabilidade, pois para esses indivíduos não será mais subsidiária. Assim, a regra do artigo 928 do CC/02, ao afirmar que o patrimônio do incapaz só será atingido se as pessoas por ele responsáveis não tiverem obrigação de fazê-lo ou não dispuserem de meios suficientes, permanece intocada quanto ao incapaz. Porém, o deficiente, por não fazer mais parte desse grupo, perderá essa importante proteção e ao ser deslocado dessa regra passa a responder com seus bens pelos seus atos. (SANTOS, 2015)

Além do fim da responsabilidade subsidiária, outras proteções dadas a incapazes também não se aplicam às pessoas com deficiência, por serem consideradas capazes, como a suspensão e impedimento dos prazos prescricionais em prejuízo dos absolutamente incapazes (arts. 198, I, e 208 do Código Civil) e a possibilidade dos relativamente incapazes ajuizarem ação contra os seus assistentes que derem causa à prescrição, ou não a alegarem oportunamente (arts. 195 e 208 do Código Civil). Cristina Stringari Pasqual e Marco Antonio Pasqual consideram que:

[...] a mudança operada trouxe consequências que certamente vão acarretar dificuldades ao operador do Direito [...] Esta nova visão da incapacidade civil exige uma reflexão cautelosa, pois apesar de inequívoco que a proteção do deficiente é imprescindível para a tutela dos direitos fundamentais, o novo regramento cria um efeito colateral contraditório ao objetivo da nova lei. (PASCOAL; PASCOAL, 2016, p. 275-276)

Deste modo, principalmente o Ministério Público deve estar atento com a aplicação do Estatuto da Pessoa com Deficiência (EPD). Deve-se conceder dignidade, acessibilidade e inclusão social às pessoas com deficiência, protegendo-as de violações a seus direitos e evitando atos de discriminação. Ivana Assis Cruz dos Santos alerta que:

[...] quando uma norma adentra ao ordenamento jurídico causando tantas mudanças, todo cuidado é pouco. Deve atentar sempre que o EPD é uma lei protetiva, cujo foco é fazer com que sujeitos com deficiência possam interagir e fazer suas escolhas, mas ao mesmo tempo não retira o poder do juiz e do Ministério Público em fiscalizar os diversos

Rev. de Processo, Jurisdição e Efetividade da Justiça | e-ISSN: 2525-9814| Maranhão | v. 3 | n. 2 | p. 36 - 53| Jul/Dez. 2017. 
procedimentos em que a atuação de curador se poderá fazer necessária. (SANTOS, 2015)

Quanto à aplicação do Estatuto da Pessoa por notários e registradores, a primeira providência que deve ser garantida é a acessibilidade. Exemplo dessa necessidade de efetivar o acesso às serventias de notas e registro é o item 20.1, g, das Normas de Serviço da Corregedoria Geral da Justiça de São Paulo que determina que as serventias devem dispor de fácil acessibilidade aos portadores de necessidades especiais, mediante existência de local para atendimento no andar térreo (cujo acesso não contenha degraus ou, caso haja, disponha de rampa, ainda que removível); rebaixamento da altura de parte do balcão, ou guichê, para comodidade do usuário em cadeira de rodas; destinação de pelo menos uma vaga, devidamente sinalizada com o símbolo característico na cor azul (naquelas serventias que dispuserem de estacionamento para os veículos dos seus usuários) e, finalmente, um banheiro adequado ao acesso e uso por tais cidadãos.

Determina, outrossim, o item 72 das Normas de Serviço de São Paulo que “os notários e registradores manterão na serventia uma versão da tabela de emolumentos em Alfabeto Braille ou em arquivo sonoro (áudio-arquivo)".

Além da acessibilidade, os notários e registradores devem garantir a prioridade de atendimento às pessoas com deficiência. Nesse sentido, o item 88, b, das mencionadas Normas de Serviço estabelece que os notários e registradores devem atender prioritariamente as pessoas com deficiência, exceto no que se refere à prioridade de registro prevista em lei. E item 88.1 dispõe que o atendimento prioritário da pessoa com deficiência é extensivo ao seu acompanhante ou atendente pessoal.

Quanto à prioridade e à acessibilidade não há maiores dificuldades de observar suas exigências e o descumprimento é facilmente constatado, podendo configurar até mesmo discriminação ou dar ensejo ao ajuizamento de ação coletiva.

A dificuldade prática começa na incapacidade. O Estatuto da Pessoa com Deficiência considerou relativamente incapaz aqueles que não puderem exprimir sua vontade. Ocorre que os relativamente incapazes são assistidos nos atos da vida civil, ou seja, o ato é praticado pelo relativamente incapaz juntamente com seu assistente. Porém, se a pessoa não consegue exprimir sua vontade não consegue participar dos atos da vida civil. José Simão vislumbra aí um equívoco do Estatuto, em suas palavras: 
[...] com a vigência do Estatuto, aquele que não puder exprimir sua vontade passa a ser assistido, ou seja, participa do ato juntamente com seu representante legal. Pergunto: se uma pessoa estiver em coma induzido por questões médicas e, portanto, temporariamente sem discernimento algum, como pode ela realizar o ato com a assistência ou auxílio? A interdição que, por fim, declarar a pessoa relativamente incapaz será inútil em termos fáticos, pois o incapaz não poderá participar dos atos da vida civil. O equívoco do Estatuto, neste tema, é evidente. A mudança legislativa é extremamente prejudicial àquele que necessita de representação e não de assistência e acarreta danos graves àquele que o Estatuto deveria proteger. (SIMÃO, 2015)

Deve-se pensar no caso de uma pessoa em coma ou em estado vegetativo. Ela não consegue exprimir qualquer vontade e, por conseguinte, deve ser ela representada, não assistida, isto é, deve ser considerada absolutamente incapaz e não relativamente incapaz. Neste ponto, Cristina e Marco Antonio Pasqual também consideram o texto aprovado equivocado:

Aquele que não possui qualquer capacidade mental de expressar a sua vontade (fato) jamais pode ser recebido pelo direito como capaz ou relativamente incapaz. O intérprete e aplicador da lei certamente enfrentará situações que deixarão clara esta realidade, o que demonstrará a necessidade de alteração na legislação [...]. (PASCOAL; PASCOAL, 2016, p. 289-290)

Deve modo, há necessidade de modificação da legislação. Mas, enquanto esta não ocorre, notários e registradores ficam sem saber como agir em tais situações. O Ministério Público deve ser compreensível os notários e registradores, tendo em vista a incongruência na lei.

Outro caso que pode suscitar dúvidas em sua aplicação é o do casamento. Primeiramente, em razão do artigo $1.550, \S 2^{\circ}$, do Código Civil que estabelece que a pessoa com deficiência mental ou intelectual em idade núbil pode contrair matrimônio, expressando sua vontade diretamente ou por meio de seu responsável ou curador. A possibilidade de o curador manifestar a vontade de casar no lugar de seu assistido vem recebendo críticas da doutrina:

A vontade é elemento essencial ao casamento e ninguém se casa senão por vontade própria. Admitir a vontade do curador como elemento suficiente para o casamento do deficiente é algo ilógico e contraria a pessoalidade do casamento, além de permitir fraudes perpetradas pelo casamento decorrente apenas da vontade do curador. O dispositivo deve ser interpretado restritivamente de acordo com a natureza personalíssima do casamento. (SIMÃO, 2015)

Ora, se a pessoa não consegue nem expressar o desejo de casar, não pode casar. Ela ao menos deve conseguir exprimir a vontade de casar. Esse é também o entendimento da Corregedoria da Justiça de São Paulo, já que no item 54.1 das Normas de Serviço estabeleceu que 
para a habilitação de casamento: "A pessoa com deficiência que manifestar vontade poderá requerer habilitação de casamento, sem assistência ou representação, sendo certo que a falta de manifestação não poderá ser suprida pela intervenção individual de curador ou apoiador”. Sendo o artigo $1.550, \S 2^{\circ}$, somente para a celebração de casamento, não para a habilitação, porque permanece em vigor o artigo 1.550, inciso IV, do Código Civil que estabelece que é anulável o casamento do incapaz de consentir ou manifestar, de modo inequívoco, o consentimento.

Outro ponto que vem gerando discussões na doutrina é a necessidade ou não de participação do curador para lavrar pacto antenupcial. Eis que a curatela afeta somente os atos relacionados aos direitos de natureza patrimonial e negocial e não alcança o direito ao matrimônio (art. 85 do Estatuto da Pessoa com Deficiência). Segundo explica Igor Fontanele de Souza:

A curatela apenas afeta negócios jurídicos relacionados aos direitos de natureza patrimonial, não alcança nem restringe os direitos de família, como adquirir matrimônio, ter filhos e exercer os direitos da parentalidade, do trabalho, eleitoral, como votar e ser votado, de ser testemunha e de obter documentos oficiais de interesse da pessoa com deficiência. (SOUZA, 2016)

O pacto antenupcial tem natureza patrimonial, eis que por ele se ajusta o regime de bens que vigorará no casamento. Desta forma, uma corrente da doutrina entende a permissão para o curatelado casar implica na permissão para escolher o regime de bens e lavrar pacto antenupcial, sem a necessidade do curador. Já outra corrente entende que se quiser lavrar pacto antenupcial, é necessária a presença do curador, eis que o pacto antenupcial tem natureza patrimonial. Tal controvérsia deve se pacificar com o tempo, com a prática e decisões no decorrer da aplicação da lei.

Diante do exposto, notários e registradores devem garantir a dignidade das pessoas com deficiência, sua inclusão e participação social. O Estatuto da Pessoa com Deficiência traz algumas incongruências que necessitam de alteração legislativa e algumas divergências que com a prática vão sendo solucionadas.

\section{CONCLUSÃO}


O Estatuto da Pessoa com Deficiência visa a assegurar a inclusão social e a proteção da dignidade das pessoas com deficiência, garantindo a civilidade e o exercício dos direitos humanos a estas.

Assim, podem promover medidas judiciais destinadas à proteção de interesses coletivos, difusos, individuais homogêneos e individuais indisponíveis da pessoa com deficiência o Ministério Público, a Defensoria Pública, a União, os Estados, os Municípios, o Distrito Federal, associação constituída há mais de 1 (um) ano, nos termos da lei civil, autarquia, empresa pública e fundação ou sociedade de economia mista que inclua, entre suas finalidades institucionais, a proteção dos interesses e a promoção de direitos da pessoa com deficiência.

O Ministério Público pode, também, instaurar inquérito civil e deve intervir, obrigatoriamente, nas ações públicas, coletivas ou individuais, em que se discutam interesses relacionados à deficiência.

Pelo Estatuto da Pessoa com Deficiência foram alteradas as normas que disciplinam a incapacidade civil, previstas no Código Civil. A deficiência deixou de ser causa de incapacidade e, portanto, foram revogados os dispositivos que consideravam incapazes os excepcionais, sem desenvolvimento mental completo, os que por deficiência mental, tenham o discernimento reduzido, e os excepcionais, sem desenvolvimento mental completo.

E os que por causa transitória ou permanente, não puderem exprimir sua vontade deixaram de ser considerados absolutamente incapazes e passaram a ser considerados relativamente incapazes.

Atualmente são considerados absolutamente incapazes apenas os menores de 16 anos e são considerados relativamente incapazes os pródigos, os maiores de dezesseis e menores de dezoito anos, os ébrios habituais e os viciados em tóxico e os que por causa transitória ou permanente, não puderem exprimir sua vontade.

Uma pessoa é considerada incapaz não pela deficiência, mas pela ausência de discernimento Deste modo, a deficiência não afeta a plena capacidade civil da pessoa, a qual pode inclusive se casar e constituir união estável.

Em razão de serem capazes, os deficientes não gozam de proteções concedidas aos incapazes, como a responsabilidade subsidiária (art.928 do Código Civil), a suspensão e impedimento dos prazos prescricionais em prejuízo dos absolutamente incapazes e a 
possibilidade dos relativamente incapazes ajuizarem ação contra os seus assistentes que derem causa à prescrição, ou não a alegarem oportunamente.

De acordo com o artigo 83 do Estatuto, notários e registradores não podem negar ou criar óbices ou condições diferenciadas à prestação de seus serviços em razão da deficiência, devendo reconhecer a capacidade legal plena do solicitante e garantir a acessibilidade, sob pena de configurar discriminação em razão de deficiência. Desta forma, os notários e registradores devem garantir a acessibilidade das pessoas com deficiência e o atendimento prioritário destas.

Porém, a aplicação prática do Estatuto pode gerar algumas dúvidas e divergências. O primeiro ponto de reflexão é que o Estatuto considerou relativamente incapazes aqueles que não puderem exprimir sua vontade (por exemplo, a pessoa em coma ou em estado vegetativo). Contudo eles deveriam ser considerados absolutamente incapazes, para serem representados, eis que não conseguem participar de atos civis assistidos por seu curador. Desta forma, deve-se alterar a legislação.

Outro ponto que pode suscitar dúvidas em sua aplicação é o artigo $1.550, \S 2^{\circ}$, do Código Civil que estabelece que a pessoa com deficiência mental ou intelectual pode contrair matrimônio, expressando sua vontade por meio de seu responsável ou curador. A possibilidade de o curador manifestar a vontade de casar no lugar de seu assistido vem recebendo críticas da doutrina, já que o artigo 1.550, inciso IV, do Código Civil determina que é anulável o casamento do incapaz de consentir ou manifestar, de modo inequívoco, o consentimento.

Outro aspecto que vem gerando discussões na doutrina é a necessidade ou não de participação do curador para lavrar pacto antenupcial. Para uma corrente da doutrina, a possibilidade de o curatelado casar implica na permissão de escolher o regime de bens e lavrar pacto antenupcial, sem a necessidade do curador. Outra corrente entende que se quiser lavrar pacto antenupcial, é necessária a presença do curador, eis que o pacto antenupcial tem natureza patrimonial.

Portanto, diante da novidade da lei, que é ainda recente, permanecem algumas dúvidas na aplicação prática dela. Quanto à lei considerar relativamente incapaz quem não puder exprimir sua vontade, a solução deve ser uma alteração na legislação. Em relação aos demais pontos, notários e registradores devem estar atentos para respeitarem o Estatuto da Pessoa com Deficiência e o Ministério Público, bem como os outros legitimados, devem observar o respeito 
aos interesses das pessoas com deficiência nas serventias notariais e registrais e, em caso de descumprimento, devem ajuizar ação coletiva.

\section{REFERÊNCIAS}

CASSETARI, Christiano. Os desafios impostos pelo Estatuto da Pessoa com Deficiência em razão das modificações na teoria das incapacidades e os seus reflexos na atividade de registradores e notários. Revista de Direito Imobiliário, São Paulo, ano 39, v. 80, jan.-jun. 2016.

LAGO, Ivan Jacopetti do. O atendimento prioritário da Lei Federal 13.146/2015 (Estatuto da Pessoa Com Deficiência) e o princípio da prioridade do registro de imóveis. Revista de Direito Imobiliário, São Paulo, ano 39, v. 80, jan-jun. 2016.

LOUREIRO, Luiz Guilherme. Registros Públicos: teoria e prática. 5. ed rev. e amp. Rio de Janeiro: Forense, 2014.

MAFFINI, Rafael. Regulação da função notarial e registral e os limites normativos do Poder Judiciário. Revista de Direito Imobiliário, São Paulo, ano 38, v. 79, dez. 2015.

MARCO, Cristhian Magnus de; SANDRINI, Katiane. A ação civil pública e a tutela dos direitos individuais homogêneos em matéria de seguridade social. Revista de Direito Brasileira, p. 111139, 2011. Disponível em: <http://www.rdb.org.br/ojs/index.php/rdb/article/viewFile/55/54>. Acesso em: 13 Jan. 2017.

OLGADO, José Lucas Rodrigues. A qualificação notarial após o advento do Estatuto da Pessoa com Deficiência. Revista de Direito Imobiliário, São Paulo, ano 39, v. 80, jan.-jun. 2016.

PASQUAL, Cristina Stringari; PASQUAL, Marco Antonio. O Estatuto da Pessoa com Deficiência como instrumento de tutela da vulnerabilidade e o novo regramento da incapacidade civil. Revista de Direito Imobiliário, São Paulo, ano 39, v. 80, jan.-jun. 2016.

PASSARELLI, Luciano Lopes. O Estatuto da Pessoa com Deficiência: reflexões aplicadas ao direito notarial e registral. Revista de Direito Imobiliário, São Paulo, ano 39, v. 80, jan-jun. 2016.

PIOVESAN, Flávia. Direitos humanos e o direito constitucional internacional. 15. ed. rev. e atual. São Paulo: Saraiva, 2015.

RAGAZZI, José Luiz. A tutela coletiva e a ACP como instrumento de garantia de direitos. Migalhas, out. 2010. Disponível em: <http://www.migalhas.com.br/dePeso/16,MI120333,61044A+tutela+coletiva+e+a+ACP+como+instrumento+de+garantia+de+direitos $>$. Acesso em: 14 jan. 2017.

REQUIÃO, Maurício. Estatuto da Pessoa com Deficiência altera regime civil das incapacidades. CONJUR, Jul. 2015. Disponível em: <http://www.conjur.com.br/2015-jul-20/estatuto-pessoadeficiencia-altera-regime-incapacidades>. Acesso em: 13 jan. 2017. 
SANTOS, Ivana Assis Cruz dos. O Estatuto da Pessoa com Deficiência e as alterações no Código Civil. Revista Jus Navigandi, Teresina, ano 20, n. 4545, 11 dez. 2015. Disponível em: <https://jus.com.br/artigos/45033>. Acesso em: 15 jan. 2017.

SIMÃO, José. Estatuto da Pessoa com Deficiência causa perplexidade. CONJUR, ago. 2015. Disponível em: <http://www.conjur.com.br/2015-ago-07/jose-simao-estatuto-pessoa-deficienciatraz-mudancas>. Acesso em: 14 jan. 2017.

SOUSA, Igor Fontenele de. O Estatuto da pessoa com deficiência. Jus.Com.Br, nov. 2016. Disponível em: <https://jus.com.br/artigos/54721/o-estatuto-da-pessoa-com-deficiencia>. Acesso em: 15 jan. 2017.

STOLZE, Pablo. Estatuto da Pessoa com Deficiência e sistema de incapacidade civil. Revista Jus Navigandi, Teresina, ano 20, n. 4411, 30 jul. 2015. Disponível em: <https://jus.com.br/artigos/41381>. Acesso em: 14 jan. 2017.

TARTUCE, Flávio. Alterações do Código Civil pela lei 13.146/2015 (Estatuto da Pessoa com Deficiência). Repercussões para o Direito de Família e Confrontações com o Novo CPC. Parte I. Migalhas, jul. 2015. Disponível em: $<$ http://www.migalhas.com.br/FamiliaeSucessoes/104,MI224217,21048Alteracoes+do+Codigo+Civil+pela+lei+131462015+Estatuto+da+Pessoa+com>. Acesso em: 14 jan. 2017. 